\title{
PERCEPÇÕES DE TRABALHADORES TÉCNICO- ADMINISTRATIVOS DE UM CURSO DE ENFERMAGEM DO ESTADO DO PARÁ SOBRE HIV/AIDS
}

Thayse Moraes de Moraes ${ }^{1}$ Bruno de Oliveira Santos ${ }^{2}$ Iaci Proença Palmeira ${ }^{2}$

Elizabeth Teixeira ${ }^{4}$

Ângela Maria Rodrigues Ferreira ${ }^{5}$

Ivaneide Leal Ataide Rodrigues ${ }^{6}$ https://orcid.org/0000-0002-3509-6503

https://orcid.org/0000-0001-9411-4700

https://orcid.org/0000-0001-9659-3565

https://orcid.org/0000-0002-5401-8105

https://orcid.org/0000-0001-6321-7512

https://orcid.org/0000-0001-9968-9546

Objetivo: Conhecer as percepções de trabalhadores técnico-administrativos de um curso de enfermagem de uma universidade pública da região Norte do país em relação ao HIV/aids. Metodologia: Estudo exploratório-descritivo, com abordagem qualitativa. Coleta de dados por meio de entrevistas semiestruturadas individuais, realizadas no período de fevereiro a maio de 2015 , tendo como participantes 30 trabalhadores técnico-administrativos. O corpus foi submetido à análise temática. Resultados: as percepções são multidimensionais pois sustentam-se em três dimensões: os saberes do senso comum (dimensão popular); os sentimentos (dimensão subjetiva); o HIV/aids - doença fatal (dimensão imagética). Conclusões: As percepções dos trabalhadores técnico-administrativos permanecem vinculadas ao conhecimento compartilhado em seus grupos de pertencimento social, recebendo influência reduzida das informações científicas circulantes no curso de enfermagem.

DESCRITORES: Enfermagem; Síndrome da Imunodeficiência Adquirida; HIV; Trabalhadores; Universidades.

\section{PERCEPTIONS OF TECHNICAL AND ADMINISTRATIVE WORKERS FROM A NURSING COURSE IN THE STATE OF PARÁ ON HIVIAIDS}

Objective: To learn the perceptions of technical and administrative workers from a nursing course at a public university in the northern region of Brazil on HIV/AIDS. Methodology: Descriptive exploratory study with a qualitative approach. Data were collected by means of semi-structured interviews from February to May 2015, with the participation of 30 technical and administrative workers. The corpus was submitted to thematic analysis. Results: Perceptions are multidimensional because they are based on three dimensions: knowledge of common sense (popular dimension); feelings (subjective dimension); and HIV/AIDS - a deadly disease (imagetic dimension). Conclusions: The perceptions of technical and administrative professionals remain associated with the knowledge shared in their social groups, receiving little influence from the scientific information circulating within the nursing course.

Descriptors: Nursing; Acquired Immunodeficiency Syndrome; HIV; Workers; Universities.

\section{PERCEPCIONES DE TRABAJADORES TÉCNICO-ADMINISTRATIVOS DE UN CURSO DE ENFERMERÍA DEL ESTADO DE PARÁ SOBRE VIH/SIDA}

Objetivo: Conocer las percepciones de trabajadores técnico-administrativos de un curso de enfermería dictado por una universidad pública del Norte de Brasil respecto del VIH/SIDA. Metodología: Estudio exploratorio-descriptivo, con abordaje cualitativo. Datos recolectados mediante entrevistas semiestructuradas individuales, realizadas entre febrero y mayo de 2015. Participaron del estudio 30 trabajadores técnico-administrativos. El corpus fue sometido a análisis temático. Resultados: Las percepciones son multidimensionales, en razón de que se sustentan en tres dimensiones: los saberes del sentido común (dimensión popular); los sentimientos (dimensión subjetiva); el VIH-/SIDA - enfermedad fatal (dimensión imagética). Conclusiones: Las percepciones de los trabajadores técnico-administrativos están directamente vinculadas con el conocimiento compartido en sus grupos de pertenencia social, recibiendo reducida influencia de la información científica difundida en el curso de enfermería.

Descriptores: Enfermería; Síndrome de Inmunodeficiencia Adquirida; VIH; Trabajadores; Universidades.

${ }^{1}$ Faculdade Integrada Brasil Amazônia e Escola Superior da Amazônia

2Universidade do Estado do Pará

${ }^{3}$ Centro Universitário Luterano de Manaus e Universidade do Estado de Amazonas

Autor correspondente: Thayse Moraes de Moraes. E-mail: thaysemmoraes@gmail.com

Enferm. Foco 2019; 10 (4): 17-20 | 17 


\section{INTRODUÇÃO}

Após mais de 30 anos, o Virus da Imunodeficiência Humana/ Síndrome da Imunodeficiência Adquirida (HIV/aids) continua a ser um dos mais sérios desafios mundiais à saúde(1). Em um período de dez anos o Brasil apresentou uma queda de $5,1 \%$ dos casos novos. Diferentemente, a região norte apresentou uma tendência linear de crescimento da taxa de detecção; em 2006, a taxa foi de 14,9 casos/100 mil hab., em 2016 aumentou para 24,8 casos/100 mil hab. O Pará, nos últimos doze anos, apresentou um incremento de 81\% (2006 - 13; 2017 - 23,6) e Belém progrediu para 74\% (2006 - 29,3;

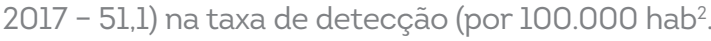

Nesse contexto, ainda que o Brasil desenvolva pesquisas desde o surgimento do HIV/aids, essas possuem uma entrada menor no campo subjetivo, com ênfase em dados epidemiológicos. Dessa forma, observa-se a importância da mudança de estratégias de cuidado, migrando de uma perspectiva curativa para a promoção à saúde. Assim, tornase importante desenvolver projetos para compreender o cuidado entre trabalhadores em suas particularidades ${ }^{3}$.

O HIV/aids tem sido um tema exaustivamente estudado em várias vertentes na produção do conhecimento, majoritariamente, com pessoas vivendo com o agravo ${ }^{4}$, estudantes de graduação em saúde ${ }^{5}$ e enfermeiros ${ }^{6}$. Detectouse uma lacuna referente ao objeto de pesquisa, este trata das percepções dos trabalhadores técnico-administrativos de uma universidade pública sobre o HIV/aids.

Assim, a inovação desse estudo refere-se à possibilidade do desencadeamento de importante eixo de reflexão referente ao papel da universidade e de cursos da área da saúde na promoção da saúde e desconstrução de estigmas, uma vez que os trabalhadores técnico-administrativos se tornam um grupo invisivel e/ou esquecido diante do conhecimento social compartilhado no espaço acadêmico.

As tendências da atualidade reforçam a relevância da comunicação, da socialização de informações, e da interação entre os profissionais de saúde e a população bem como entre as instituições de ensino na área da saúde, em especial cursos de enfermagem, e seus trabalhadores. Assim, o objetivo do estudo foi conhecer as percepções sobre o HIV/ aids de trabalhadores técnico-administrativos de um curso de enfermagem em uma universidade pública do estado do Pará.

\section{METODOLOGIA}

\section{Tipo de estudo}

Trata-se de estudo exploratório e descritivo com abordagem qualitativa.

\section{Participantes do estudo}

Participaram 30 trabalhadores técnico-administrativos, representando $71,42 \%$ do total de 42 trabalhadores. Foram critérios de inclusão: ser trabalhador técnico-administrativo, contratado ou concursado, no exercício de suas funções laborais. Foram excluídos 12 trabalhadores em gozo de férias ou licença no período das entrevistas.

\section{Local do estudo}

Realizado nas dependências de um Curso de Enfermagem de uma universidade pública do estado do Pará.

\section{Coleta de dados}

A construção das informações foi de fevereiro a maio de 2015, por meio da entrevista semiestruturada individual, com duração de 30 a 40 minutos, com roteiro formado por duas partes: questões fechadas - referente aos dados sociodemográficos, e questões abertas - direcionadas à apreensão de suas percepções sobre o HIV/aids (O que é? Quem adoece? Como adoece? O que sabe? Como sabe? Qual o efeito do que sabe?)

A abordagem ocorreu nos setores de trabalho: procediase as apresentações e os convites para se dirigirem à outra sala para consecução das entrevistas. Transcrevia-se as entrevistas na integra, que passaram a constituir o corpus de análise.

\section{Procedimentos de análise dos dados}

Submeteu-se o corpus à análise de conteúdo temática(7): 1) Pré-análise- fez-se leitura flutuante, identificou-se temas que se repetiam frequentemente, foram recortados do texto em unidades de categorização para análise; 2) Exploração e tratamento do material - análise acurada, visualização de temas centrais e comuns nos relatos; 3) Interpretação dos resultados - associou-se os dados obtidos aos debates dos estudiosos do tema/objeto, significou-se e interpretou-se os resultados, buscando as inferências ocultas em suas falas.

\section{Procedimentos éticos}

Estudo aprovado pelo Comitê de Ética em Pesquisa do Curso de Graduação em Enfermagem da Universidade do Estado do Pará, parecer no 840.486 e todos os participantes assinaram o Termo de Consentimento Livre e Esclarecido (TCLE).

\section{RESULTADOS}

\section{Caracterização dos trabalhadores técnico-administrativos}

Dentre os participantes, identificou-se 16 mulheres e 14 homens, apontando um equilibrio entre os gêneros; faixa 
etária entre 26 e 35 anos (10); católicos (16); renda entre R\$ 2.000,00 e R\$2.900,00 (11) e tinham nível superior (13).

A aquisição de conhecimentos sobre o tema, para os participantes, foi predominantemente por meio de mídia televisiva e conversas no cotidiano (22), já que apenas oito - adquiriram por meio de livros. A análise de conteúdo, possibilitou a identificação de três categorias centrais: os saberes sobre o HIV/aids (dimensão popular); os sentimentos despertados pela síndrome (dimensão subjetiva); e o HIV/aids - doença fatal (dimensão imagética).

\section{Os saberes sobre o HIV/aids (dimensão popular)}

Os relatos dos entrevistados, ao serem questionados quanto ao modo de transmissão da sindrome, estavam relacionados ao sexo oral, relações sexuais desprotegidas e transmissão de sangue. Diante da tentativa de entender o processo referente às práticas preventivas adotadas, o preservativo apareceu como método de escolha, assim como o não compartilhamento de seringas e agulhas, observado em: "A transmissão ocorre através de sexo oral, ato sexual sem proteção, transfusão de sangue e material contaminado, como seringas, tanto com o uso de drogas, como nas questões de transfusões de sangue" (E3); "Para evitar o contágio do HIV/aids tem que usar o preservativo!" (E2).

Em relação ao HIV/aids, observa-se que, mesmo entre os entrevistados com maior nível de escolaridade, há um conhecimento ainda incipiente em relação às formas de transmissão e prevenção. Além disso, o acesso à informação sobre IST/aids foi obtido por meio de mídias televisivas e conversas no cotidiano. Apesar disso, conseguimos observar algumas informações corretas sobre as formas de transmissão e "especulações" produzidas pelo imaginário popular, como no relato a seguir: "Tem que se precaver acima de tudo, com o uso de preservativos" (E4).

\section{Os sentimentos despertados pela síndrome (dimensão subjetiva)}

Os trabalhadores integram, em seus discursos, dimensões subjetivas como medo, preocupação, angústia e temor, ou seja, sentimentos negativos que afastam as pessoas e estão relacionados com a possibilidade da contaminação à infecção do HIV/aids. As falas a seguir expressam esses sentimentos: "Eu teria mais cuidado, mas não iria mudar minha relação com ele [...]" (E14); "Eu não posso dizer que não seria preconceituosa [...]. O HIV/aids é uma doença muito perigosa e eu não quero morrer assim" (E23).

Outro aspecto a ser destacado refere-se ao fato de alguns participantes não citarem o nome da síndrome, como se a menção à sigla trouxesse consigo desconforto, referindo-se à aids como "essa doença" e "essa coisa": "Lá perto da minha casa tem uma criança [...]. Que pegou "essa doença" da mãe, que se contaminou através de uma relação extraconjugal" (E2); "Eu ouvi falar sobre "essa coisa" porque a filha de um amigo pegou o vírus com 16 anos, através de relação sexual com o namorado dela, porque ele era viciado em drogas [...]" (E7).

\section{HIV/aids - doença fatal (dimensão imagética)}

Essa categoria emergiu a partir de verbalizações que remetiam a imagens que comparavam a sindrome à história do câncer, uma vez que ambas concebem a mesma rotulação de gravidade: "Acho que o HIV/aids é o caminho do cemitério. Acho que é igual ao câncer, pode até tentar tratar, mas hora ou outra vai morrer" (E15); "Eu não ficaria sem esperança. Daqui a dois... Cinco anos, se descobre a cura de qualquer coisa" (E30).

Quando pensavam em alguém com HIV/aids, o estereótipo de pessoas com lipodistrofia tornou-se um marcador da sindrome, ratificado nas expressões como "pessoa seca", "meio maracujá" e "pessoa franzina" sendo estas nominações pejorativas à aparência da pessoa com aids: "Geralmente, a pessoa é seca, ela é tipo um maracujá, uma pessoa franzina [...]" (E30).

Ainda na perspectiva de imagem, a magreza excessiva foi associada à imagem de Cazuza, cantor brasileiro que morreu em consequência de infecções oportunistas decorrentes do HIV/aids, como mostrado nos relatos: "Associo ao Cazuza, ele ficou muito magro e morreu de HIV/aids" (E3); "O Cazuza pegou a sindrome no auge, o início dessa doença no Brasil, como ele assumiu, a repercussão foi bem forte" (E25).

\section{DISCUSSÃO}

Os depoimentos apresentam importantes apontamentos em relação a um grupo específico, como trabalhadores técnico-administrativos em seu ambiente laboral e o espaço universitário (formador de profissionais da saúde), contexto em que se espera o adequado acesso às informações para a prevenção da síndrome, além do próprio perfil dos participantes em relação à escolaridade, posto que a maioria possuía nivel superior completo, o que originou a primeira categoria relacionada aos saberes sobre o HIV/aids (dimensão popular), tais como as praticas preventivas adotadas e os meios de acesso à informação sobre HIV/aids.

Uma estratégia sinalizada pelos participantes para a prevenção do HIV/aids, foi o uso do preservativo às práticas sexuais propriamente $\operatorname{ditas}^{(8)}$. Ainda referente à prevenção, o não compartilhamento de seringas e agulhas foram apontados, resultado similar a outros estudos ${ }^{(9,10)}$. Tal fato é embasado no conhecimento de anos anteriores quanto a vulnerabilidade dos usuários de drogas ${ }^{(11)}$. 
Os resultados chamaram atenção quanto às formas de obtenção de informações por meio de mídias televisivas, que exercem o seu papel apenas como provedora de noticias, sem muita preocupação com a exatidão sobre a sindrome (12). Essa realidade pode justificar informações incompletas, como por exemplo, a falta de conhecimento sobre os locais de realização do teste anti-HIV, que, se realizado no início da infecção, propicia sua identificação rápida, resultando em uma maior taxa de sobrevivência e maior adesão ao tratamento (13). O estudo confirma a necessidade de implementação de estratégias como palestras, estudos de casos, rodas de conversa, de modo a se promoverem ações educativas, buscando a aderência às medidas de controle ${ }^{(14)}$.

Nesse contexto, explorou-se mais o assunto e surgiu a segunda categoria: Os sentimentos despertados pela sindrome (dimensão subjetiva), apontando o medo, a preocupação, a angústia e o temor quanto à possibilidade de contaminação à infecção pelo HIV. Esses sentimentos negativos são comuns entre os profissionais de saúde, ao comunicarem o diagnóstico de HIV/aids aos usuários, manifestando o medo do preconceito e do abandono decorrente da discriminação da sindrome ${ }^{(15)}$.

Esse sentimento restringe as relações afetivo-sexuais das pessoas que vivem com HIV/aids, interferindo em suas e enclausurando suas sexualidades por receio de expor-se, causando angústia, repressão e sentimentos de negação(16).

A história da síndrome revela que, no imaginário social, a doença ainda é considerada como vergonhosa e pecaminosa. Fato este que pode servir de explicação para a não citação do nome do vírus e da síndrome, como se sua menção trouxesse consigo vergonha e castigo divino. Na Bíblia há uma citação para rotular "pecadores", dentre estes, os Homens que fazem sexo com homens (HSH), por irem de encontro aos seus dogmas, uma vez que o HIV foi primeiramente diagnosticado neste grupo. Desse modo, as doenças ligadas ao comportamento sexual ainda são moralmente repreendidas e apontadas culturalmente como enfermidades procuradas e merecidas ${ }^{(17)}$.

A terceira categoria contemplou o HIV/aids - doença fatal (dimensão imagética). Eles associaram, de imediato, à história do câncer, ao expressarem a imagem que lhes vinha à mente quando pensavam em alguém com HIV/aids. Tal fato pode ser explicado porque o HIV/aids, nos primeiros discursos produzidos pela medicina, havia sido rotulado de "câncer gay" - uma vez que a comunidade homoafetiva constituía um dos seus primeiros grupos de vulnerabilidade ${ }^{(17)}$.

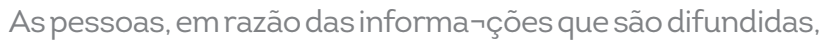
podem utilizar a morte para explicar o desenvolvimento do HIV/aids no homem, semelhante ao que aconteceu com o câncer há alguns anos. Em um estudo realizado com profissionais da saúde, foi referido, o mito que ainda perdura sobre o vírus do HIV, que o vincula à morte e ao fim da vida. Por outro lado, também foi mencionado que a "cronificação" do vírus faz as pessoas não se preocuparem em ter cuidado quanto a sua contaminação(15).

As mudanças corporais sofridas e percebidas foram relacionadas diretamente à lipodistrofia. Nessa conjuntura, tornou-se um marcador do HIV/aids. Os aspectos corporais denunciam o estado da pessoa, como: magreza, queda de cabelo e adoecimentos frequentes, sinais que remetem à imagem de um corpo esteticamente deformado pelas mazelas trazidas pelo HIV/aids. O corpo materializa a síndrome, tornando pública as vivências de ordem particular do indivíduo. Assim, resta, ao enfermo, o isolamento nosocomial ou ainda o "afastar-se" das pessoas, como se o adoecimento pelo HIV/aids fosse uma circunstância incompativel com a vida em sociedade ${ }^{(6)}$

Ainda na dimensão imagética, houve participantes que relacionaram a magreza excessiva à imagem de Cazuza, cantor brasileiro que morreu em consequência de infecções oportunistas decorrentes da aids. Cazuza foi uma das primeiras figuras públicas a assumir, em 1989, que era soropositivo e a falar abertamente sobre sua orientação sexual. Na ocasião do diagnóstico, pesava 68 quilos, em pouco tempo, chegou aos 40k, e faleceu em julho de 1990. Mesmo após 28 anos sem Cazuza, sua imagem corroída pela aids atravessa a barreira do tempo, se materializa e serve de parâmetro para as percepções referentes à doença ${ }^{(18)}$.

\section{Limitações do estudo}

Referem-se aos resultados se circunscreverem a uma única instituição de ensino, limitando o grupo de participantes. Não podendo, assim, ser posto como realidade de outras instituições e tampouco replicá-lo em outros contextos.

\section{Contribuições para a prática}

Conhecer a percepção dos trabalhadores sobre o HIV/ aids em uma instituição de educação superior para formação de profissionais de saúde, pode contribuir para a reflexão sobre o tema, uma vez que traz à tona saberes, preconceitos, dúvidas e temores vivenciados por eles no âmbito do HIV/ aids, assumindo particular importância, ao servir de subsídios para o planejamento de ações educativas aos membros de sua comunidade acadêmica.

\section{CONSIDERAÇÕES FINAIS}

O objetivo do estudo foi alcançado, pois passou-se a conhecer as percepções sobre o HIV/aids de trabalhadores técnico-administrativos de um curso de enfermagem em uma universidade pública da região Norte do país. 
$\mathrm{Na}$ atualidade, dispõe-se de um acervo maior de informações científicas e tecnologias para lidar e cuidar de pessoas com a sindrome, que há três décadas. Todavia, tal evolução não têm sido capaz de contribuir para a redução da prevalência da epidemia (especialmente na região Norte), e tampouco reduzir o estigma e preconceito atrelados à sindrome.

As percepções dos trabalhadores técnico-administrativo permanecem vinculadas ao conhecimento compartilhado em seus grupos sociais, recebendo pouca influência das informações cientificas circulantes no curso de enfermagem. Isso interfere em suas percepções e atitudes ante o HIV/aids.

Os resultados, desta pesquisa, apresentam indícios de uma trajetória que urge por mudanças e rupturas de pensamentos e comportamentos arcaicos, norteados por dogmas culturais e atrelados à história do HIV e aids. Tais achados apontam a importância de circularem informações apropriadas sobre o tema nos contextos institucionais, contribuindo para a construção e divulgação de saberes e atitudes que levem à desconstrução de tabus e estereótipos, e à adoção de medidas de autoproteção contra o HIV/aids.

\section{Contribuição dos autores}

Concepção e/ou desenho, análise e interpretação dos dados, redação do artigo, revisão crítica, revisão: Thayse Moraes de Moraes, Bruno de Oliveira Santos, Iaci Proença Palmeira, Elizabeth Teixeira; Ivaneide Leal Ataide Rodrigues, Ângela Maria Rodrigues Ferreira.

\section{REFERÊNCIAS}

1. Joint United Nations Programme on HIV/AIDS (UNAIDS). A ONU e a resposta à aids no Brasil. UNAIDS [Internet]. 2016 [cited 2018 Jun 30] Available from: http://unaids.org.br/wp-content/uploads/2016/03/A-ONU-e-a-resposta-PORTUGU\%C3\%8AS.pdf.

2. Ministério da Saúde (BR). Boletim Epidemiológico - HIV Aids. Julho de 2017 a junho de 2018. Ministério da Saúde [Internet]. 2018 [cited 2018 Dez 02]. Available from: http://www.aids.gov.br/pt-br/pub/2018/boletim-epidemiologico-hivaids-2018.

3. Hamann C, Pizzinato A, Weber JLA, Rocha KB. Narrativas sobre risco e culpa entre usuários e usuárias de um serviço especializado em infecções por HIV: implicações para o cuidado em saúde sexual. Saúde e Sociedade [Internet]. 2017 [cited 2018 Dez 03]; 26: 651-663. Available from: http:// www.scielo.br/scielo.php?pid=S0104-12902017000300651Escript=sci_ abstractEtlng=pt.

4. Jesus GJ, Oliveira LB, Caliari JS, Queiroz AA, Gir E, Reis RK. Dificuldades do viver com HIV/Aids: Entraves na qualidade de vida. Acta Paul Enferm [Internet]. 2017 [cited 2018 Dez 01]; 30(3):301-7. Available from: http:// www.scielo.br/scielo.php?pid=S0103-210020170003003018script=sci_abstract\&tlng=pt.

5. Magalhães VCS, Oliveira DL, Prado FO. Conhecimento, percepção de risco e atitudes de acadêmicos de Odontologia sobre HIV/ AIDS. RGO, Rev Gaúch Odontol [Internet]. 2015 [cited 2018 Dez 02]; 63(3):291-300. Available from: http://www.scielo.br/scielo.php?pi$\mathrm{d}=$ S1981-86372015000300291\&script=sci_abstractEtlng=pt.

6. Araújo WJ, Quirino EMB, Pinho CM, Andrade MS. Percepção de enfermeiros executores de teste rápido em Unidades Básicas de Saúde. Rev Bras Enferm [Internet]. 2018 [cited 2018 Nov 15]:71(supl1):676-81. Available from: http://www.scielo.br/pdf/reben/v7lsl/pt_0034-7167-reben-71-s1-0631.pdf.

7. Bardin L. (2016). Análise de conteúdo. São Paulo: Edições 70.

8. Amaral RS, Carvalho STRF, Silva FMA, Dias RS. Soropositividade para hiv/aids e caracteristicas sociocomportamentais em adolescentes e adultos jovens. Rev Pesq Saúde [Internet]. 2017 [cited 2018 Nov 17]:18(2):108113. Available from: http://www. periodicoseletronicos.ufma.br/index.php/ revistahuufma/article/view/8384/5209.

9. Villarinho MV, Padilha MI. Sentimentos relatados pelos trabalhadores da saúde frente à epidemia da aids (1986-2006). Texto Contexto Enferm [Internet]. 2016 [cited 2018 Nov 10];25(1):e0010013. Available from: http:// www.scielo.br/pdf/tce/v25n1/0104-0707-tce-25-01-0010013.pdf.

10. Nardelli GG, Malaquias BSS, Gaudenci EM, Ledic CS, Azevedo NF Martins VE, et al. Conhecimento sobre sindrome da imunodeficiência humana de idosos de uma unidade de atenção ao idoso. Rev Gaúcha
Enferm [Internet]. 2016 [cited 2018 Nov 09]:37(esp):e2016-0039. Available from: http://www.scielo.br/pdf/rgenf/v37nspe/0102-6933-rgenf-1983-14472016esp2016-0039.pdf.

11. Bittencourt GKGD, Moreira MASP, Meira LCS, Nóbrega MML, Nogueira JA, Silva AO. Concepções de idosos sobre vulnerabilidade ao HIV/aids para construção de diagnósticos de enfermagem. Rev Bras Enferm [Internet]. 2015 [cited 2018 Nov 10];68(4):579-85. Available from: http://www. scielo.br/pdf/reben/v68n4/0034-7167-reben-68-04-0579.pdf.

12. Araujo ACC. A AIDS na capa de O Globo e da Folha de São Paulo do ano de 2001. Rev Eletrônica do Instituto de Humanidades [Internet]. 2017 [cited 2018 Nov 11]:18(44):109-124. Available from: http://publicacoes.unigranrio.edu.br/index.php/reihm/article/view/4836/2574.

13. Sousa RMRB, Frota MMA, Castro C, Kendall BC, Kerr LRFS. Percepções de mulheres profissionais do sexo sobre acesso do teste HIV: incentivos e barreiras. Saúde em Debate [Internet]. 2017 [cited 2018 Nov 10]:41(113):513-525. Available from: http://www.scielo.br/pdf/sdeb/ v4ln113/0103-1104-sdeb-41-113-0513.pdf.

14. Linder V, Chaves SE, Strapasson MR. Percepções de mulheres vivendo com o virus da imunodeficiência humana acerca da impossibilidade de amamentar. Enferm. Foco [Internet] 2016 [cited 2018 Dez 02]; 7(2): 07-11. Available from: http://revista.cofen.gov.br/index.php/enfermagem/article/viewFile/784/311

15. Massignani LM, Rabuske MM, Backes MS, Crepaldi MMA. Comunicação de diagnóstico de soropositividade HIV e aids por profissionais de saúde. Psicol Argum [Internet]. 2017 [cited 2018 Nov 05];32(79) Supl 1:65-75. Available from: https://periodicos.pucpr.br/index.php/psicologiaargumento/article/view/20367/19635.

16. Oliveira FBM, Queiroz AAFLN, Sousa AFL, Moura MEB, Reis RK. Orientação sexual e qualidade de vida de pessoas vivendo com HIV/aids. Rev Bras Enferm [Internet]. 2017 [cited 2018 Nov 20];70(5):1057-62. Available from: http://www.scielo.br/pdf/reben/v70n5/pt_0034-7167-reben-70-05-1004.pdf.

17. Brito FLCB, Rosa JM. "OS LEPROSOS DOS ANOS 80", "CÂNCER GAY, "CASTIGO DE DEUS": homossexualidade, AIDS e capturas sociais no Brasil dos anos 1980 e 1990. Revista Observatório [Internet]. 2018 [cited 2018 Nov 30]:4(1):751-778. Available from: https://sistemas.uft.edu.br/periodicos/index.php/observatorio/article/view/3175/12225.

18. Herzlich C, Pierret J. Uma doença no espaço público. A AIDS em seis jornais franceses. Physis - Revista de Saúde Coletiva [Internet]. 2005 [cited 2018 Nov 29]; 15:71-101. Available from: http://www.scielo.br/pdf/ physis/v2nl/Ol.pdf. 